\title{
MECHANISMS IN ENDOCRINOLOGY An update in the genetic aetiologies of combined pituitary hormone deficiency
}

\author{
Frederic Castinetti ${ }^{1,2,3, *}$, Rachel Reynaud ${ }^{1,3,4, *}$, Alexandru Saveanu ${ }^{1,2,3,5}$, \\ Nicolas Jullien', Marie Helene Quentien ${ }^{1}$, Claire Rochette 1,2,3, Anne Barlier 1,2,3,5, \\ Alain Enjalbert ${ }^{1,3,5}$ and Thierry Brue ${ }^{1,2,3}$ \\ ${ }^{1}$ Aix-Marseille Université, CNRS, Centre de Recherche en Neurobiologie et Neurophysiologie de Marseille CRN2M \\ UMR 7286, 13344 cedex 15 Marseille, France, ${ }^{2}$ Department of Endocrinology, APHM, Hôpital La Conception, Service \\ d'Endocrinologie, Diabète et Maladies Métaboliques, 13385 cedex 5 Marseille, France, ${ }^{3}$ Centre de Référence des \\ Maladies Rares d'Origine Hypophysaire DEFHY, 13385 cedex 15 Marseille, France, ${ }^{4}$ APHM, Hôpital Timone Enfants, \\ Service de Pédiatrie Multidisciplinaire, 13385 cedex 5 Marseille, France and ${ }^{5}$ APHM, Hôpital de la Conception, \\ Laboratoire de Biologie Moléculaire, 13005 Marseille, France \\ *(F Castinetti and R Reynaud contributed equally to this work)
}

\author{
Correspondence \\ should be addressed \\ to T Brue \\ Email \\ thierry.brue@ap-hm.fr
}

\begin{abstract}
Over the last 5 years, new actors involved in the pathogenesis of combined pituitary hormone deficiency in humans have been reported: they included a member of the immunoglobulin superfamily glycoprotein and ciliary G protein-coupled receptors, as well as new transcription factors and signalling molecules. New modes of inheritance for alterations of genes encoding transcription factors have also been described. Finally, actors known to be involved in a very specific phenotype (hypogonadotroph hypogonadism for instance) have been identified in a wider range of phenotypes. These data thus suggest that new mechanisms could explain the low rate of aetiological identification in this heterogeneous group of diseases. Taking into account the fact that several reviews have been published in recent years on classical aetiologies of CPHD such as mutations of POU1F1 or PROP1, we focused the present overview on the data published in the last 5 years, to provide the reader with an updated review on this rapidly evolving field of knowledge.
\end{abstract}

\section{Introduction}

Pituitary development is a complex process requiring the coordinated interplay of specific and non-specific pituitary transcription factors and signalling pathways (Fig. 1). Anomalies of pituitary development are usually due to mutations of the genes coding for specific or non-specific transcription factors. Since the first report of a POU1F1 mutation in a patient with combined growth hormone (GH) and thyroid-stimulating hormone (TSH) deficiencies, huge progress has been made to try to decipher the pituitary development code. Most non-specialized

\section{Invited Author's profile}

Thierry Brue, MD, PhD, is a professor of endocrinology at the Aix-Marseille University (Marseille, France), and endocrinologist at the Conception University Hospital where he currently serves as Head of Department, Head of the 'ENDO' Division (Endocrinology, Nutrition, Diabetes and Obesity), and coordinator of the rare disease reference centre for pituitary disorders (DEFHY). Prof. Brue's research activities include clinical research in pituitary disorders and experimental research as leader of a team on pituitary pathophysiology in Alain Enjalbert's Laboratory, and as coordinator of a network on genetically determined pituitary hormone deficiency (GENHYPOPIT). A member of the French, American, and European endocrine societies, Prof. Brue has co-authored about 200 peer-reviewed articles.

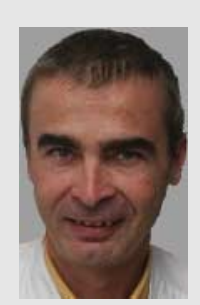

(C) 2016 European Society of Endocrinology Printed in Great Britain
Published by Bioscientifica Ltd. 


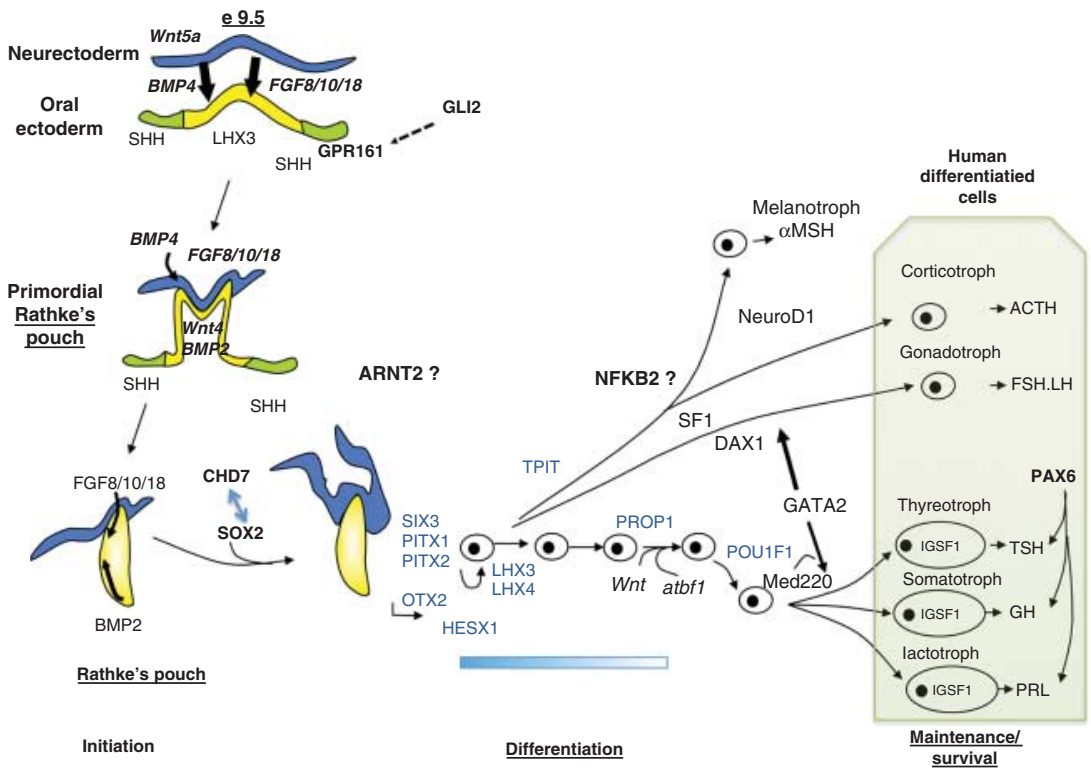

\section{Figure 1}

Brief overview of pituitary ontogenesis.

endocrinologists are now aware of the fact that gene anomalies affecting transcription factors like PIT1, PROP1 or HESX1 may lead to combined pituitary hormone deficiencies. Rather than describing again the whole set of phenotypes induced by classical mutations, we decided to focus on the new findings published on the topic over the last 5 years. An exhaustive PubMed research has been performed with the terms 'hypopituitarism', 'congenital', 'pituitary deficiency', 'GH deficiency'TSH or adrenocorticotropin hormone (ACTH) deficiency', 'gonadotroph deficiency' and 'magnetic resonance imaging (MRI) anomalies'. For space constraints, we excluded all the data that were dealing with isolated pituitary deficiency to focus on studies dealing with combined pituitary hormone deficiency. We also chose not to detail the wellknown phenotypes of patients carrying PROP1, POU1F1, HESX1, or OTX2 mutations, as all of them have previously been reviewed (1), and the global picture of these phenotypes did not significantly change since then. For each transcription factor/pathway/protein reported, we will first begin with a brief introduction on the potential mechanisms leading to hypopituitarism - when identified - we will then summarize what was known about patient phenotypes before 2010, and finally provide an update on the major findings reported over the last 5 years.

A classical way to illustrate pituitary development is to represent the cascade of signalling and transcription factors in mouse. However such a presentation would be irrelevant for most of the new actors described in this review since the precise timing of their expression is currently unknown. To make comparisons of phenotypes possible, we present in Table 1 the summary of the phenotypes associated to the anomalies described thereafter, showing separately the classical expected phenotype and the changes brought by the literature published over the last 5 years.

\section{Novel mechanisms}

\section{TSH deficiency, macro-orchidism and IGSF1}

IGSF1 gene encodes a glycoprotein of the plasma membrane immunoglobulin superfamily (Immunoglobulin Superfamily Member 1): expression of its mRNA is found in the developing Rathke's pouch, in adult pituitary and in the testes, whereas IGSF1 protein is detected specifically in GH, prolactin (PRL) and TSH-secreting cells. IGSF1 deficiency syndrome has been reported in patients with TSH deficiency and macro-orchidism, in a context of loss of function mutations or deletions of the IGSF1 gene. IGSF1 variants were identified by a wholeexome approach, and then confirmed by classical Sanger sequencing. Eight novel mutations and two deletions were reported in males, suggesting an X-linked disorder (2). Complete phenotypic data were based on 24 males (hemizygotes) carrying IGSF1 mutations (from ten 
Table 1 Summary of the new and classical phenotypes in patients with CPHD.

\begin{tabular}{|c|c|c|c|}
\hline Protein & Transmission & Expected phenotype & Novel phenotype \\
\hline \multicolumn{4}{|c|}{ Fibroblast growth factor family } \\
\hline FGF8 & Autosomal recessive & Hypogonadotrophic hypogonadism & $\begin{array}{l}\text { GH deficiency, ACTH deficiency, TSH } \\
\text { deficiency, diabetes insipidus, SOD, } \\
\text { corpus callosum agenesis }\end{array}$ \\
\hline FGFR1 & Autosomal dominant & Hypogonadotrophic hypogonadism & $\begin{array}{l}\text { Septo-optic dysplasia, pituitary } \\
\text { deficiencies up to panhypopitui- } \\
\text { tarism, ectopic posterior pituitary }\end{array}$ \\
\hline \multicolumn{4}{|c|}{ G protein-coupled receptor } \\
\hline PROKR2 & $\begin{array}{l}\text { Autosomal dominant } \\
\text { or recessive }\end{array}$ & Hypogonadotrophic hypogonadism & $\begin{array}{l}\text { Septo-optic dysplasia, congenital } \\
\text { hypopituitarism }\end{array}$ \\
\hline GPR161 & Autosomal recessive & Unknown & $\begin{array}{l}\text { GH deficiency, anterior pituitary } \\
\text { hypoplasia, EPP }\end{array}$ \\
\hline \multicolumn{4}{|c|}{ Immunoglobulin superfamily } \\
\hline IGSF1 & X-linked & Unknown & $\begin{array}{l}\text { TSH deficiency, partial GH deficiency, } \\
\text { undetectable PRL, macro-orchidism }\end{array}$ \\
\hline \multicolumn{4}{|c|}{ Transcription factor } \\
\hline ARNT2 & Autosomal recessive & Unknown & $\begin{array}{l}\text { Diabetes insipidus, ACTH deficiency, } \\
\text { inconstant GH and LH/FSH defici- } \\
\text { ency, anterior pituitary hypoplasia, } \\
\text { EPP, hypoplastic frontal and } \\
\text { temporal lobes, thin corpus callo- } \\
\text { sum, delayed brain myelination, } \\
\text { prominent forehead, retrognathia }\end{array}$ \\
\hline CHD7 & Autosomal dominant & $\begin{array}{l}\text { CHARGE syndrome, inconstant GH, } \\
\text { LH/FSH, TSH deficiency }\end{array}$ & Ectopic posterior pituitary \\
\hline GLI2 & Autosomal dominant & Holoprosencephaly & $\begin{array}{l}\text { GH deficiency, ectopic posterior } \\
\text { pituitary, postaxial polydactily }\end{array}$ \\
\hline LHX3 & $\begin{array}{l}\text { Autosomal recessive } \\
\text { (homozygous or } \\
\text { compound heterozygous) }\end{array}$ & $\begin{array}{l}\text { GH, TSH, LH/FSH deficiencies, inconstant } \\
\text { ACTH deficiency, pituitary hypo- or } \\
\text { hyperplasia, head and neck rotation } \\
\text { anomalies, vertebral anomalies, hearing } \\
\text { deficits }\end{array}$ & $\begin{array}{l}\text { Unchanged (heterozygote patients } \\
\text { might have a mild phenotype) }\end{array}$ \\
\hline LHX4 & $\begin{array}{l}\text { Autosomal dominant } \\
\text { or recessive }\end{array}$ & $\begin{array}{l}\text { GH deficiency, inconstant pituitary } \\
\text { deficiencies, pituitary hypoplasia, } \\
\text { ectopic posterior pituitary, Chiari } \\
\text { syndrome, corpus callosum hypoplasia }\end{array}$ & $\begin{array}{l}\text { Addition of respiratory distress } \\
\text { and mid facial hypoplasia in } \\
\text { homozygous state }\end{array}$ \\
\hline NFKB2 & Autosomal dominant & Unknown & $\begin{array}{l}\text { DAVID syndrome (variable immune } \\
\text { deficiency and ACTH deficiency), } \\
\text { inconstant partial GH/TSH } \\
\text { deficiencies }\end{array}$ \\
\hline PAX6 & Autosomal dominant & Eye defect, partial ACTH deficiency & $\begin{array}{l}\text { GH deficiency, pituitary hypoplasia, } \\
\text { thin stalk }\end{array}$ \\
\hline SOX2 & Autosomal dominant & $\begin{array}{l}\text { Gonadotroph deficiency, inconstant TSH, } \\
\text { ACTH deficiencies, pituitary hypoplasia, } \\
\text { microphtalmia, mental retardation }\end{array}$ & $\begin{array}{l}\text { Inconstant partial GH and LH/FSH } \\
\text { deficiency }\end{array}$ \\
\hline
\end{tabular}

different families) (3): they all presented with neonatal TSH deficiency as well as per and post-pubertal macroorchidism; $67 \%$ of the patients had undetectable PRL levels, and 13\% had transient GH deficiency. Even with an increased testicle volume, they all had delayed puberty, with low testosterone level. Finally, despite optimal substitutive treatments, patients were mainly overweight or had a metabolic syndrome at adult age. Eighteen heterozygous females were also evaluated: 33\% had TSH deficiency, 11\% had undetectable PRL level and none had GH deficiency. The precise mechanisms leading to macro-orchidism or even to pituitary deficiency are up to now still unknown.

\section{Pituitary stalk interruption syndrome and GPR161}

G protein coupled receptor 161 (GPR161) is a ciliary $G$ protein-coupled receptor that is expressed widely in the developing embryo including in neural folds, the pituitary and the hypothalamus of mouse and human. The reasons why anomalies of this receptor would lead to hypopituitarism is unknown even if interactions with 
glioma-associated oncogene 2 (GLI2), another transcription factor involved in pituitary development, have been described: Gpr161 is indeed a key negative regulator of Sonic hedgehog (Shh) pathway (4), the pituitary target of which is GLI2. This would suggest that gain-of-function mutations of GPR161 could lead to abnormal pituitary development by repressing the Shh pathway, which is crucial for hypothalamic and pituitary development, as detailed later.

Two female siblings with short stature due to GH deficiency, anterior pituitary hypoplasia and ectopic posterior pituitary were recently reported as carrying a homozygous L19Q GPR161 mutation in a heterozygous state. Hypoglycaemia was observed in the first sister, who also presented with diabetes insipidus and TSH deficiency few years after diagnosis. The second sister had isolated GH deficiency, and similar MRI findings. Finally, both sisters also had anatomical anomalies with a short 5th finger, congenital alopecia, and ptosis of the left eye. The variant was first identified by a whole-exome sequencing approach. Its pathogenicity was suggested by its absence in large single-nucleotide polymorphisms (SNP) databases, and a concordant mode of inheritance (both unaffected parents, and unaffected siblings were heterozygous). Unfortunately functional studies did not manage to show any difference with WT GPR161 (5).

\section{Novel transcription factors}

\section{The complex phenotype associated with a rare ARNT2 mutation}

Aryl hydrocarbon receptor nuclear translocator 2 (ARNT2) is a helix-loop-helix transcription factor. Its precise roles during the pituitary and brain development are imperfectly known. In mice, Arnt2 is expressed at high level in the cortex, the hypothalamus and the retina during development. Interestingly, Arnt2 null mice do not display morphological abnormalities but die shortly after birth. In human embryos, the expression profile of this factor is roughly the same. Its involvement in a complex syndrome of combined pituitary hormone deficiency associated with a severe extra-pituitary phenotype was identified through exome sequencing in a large consanguineous Saudi Arabian family. The six children presented shortly after birth central diabetes insipidus and corticotroph deficiency; four had thyrotroph deficiency, two had GH deficiency and one had gonadotroph deficiency with undescended testes. Brain MRI showed pituitary and extra-pituitary anomalies: hypoplastic anterior pituitary and pituitary stalk interruption, hypoplastic frontal and temporal lobes, thin corpus callosum, and brain delay in myelination; a lack of pupil response to light was reported with post-retinal eye anomalies. Finally, all of the children were dysmorphic with a prominent forehead, deep-set eyes, a well-grooved philtrum, and retrognathia. Microcephaly progressively appeared in all patients. All children carried a homozygous c.1373_1374dupTC ARNT2 variant. As expected, both parents were heterozygous. This duplication induces a premature stop codon and nonsense mediated decay mechanisms (6).

\section{DAVID syndrome and NFKB2}

In 2012 we reported the association of pituitary deficiency (mainly ACTH deficiency), while one patient also presented with partial GH and TSH deficiencies and variable immune deficiency (VID) in several patients from three different pedigrees. This association was called DAVID syndrome (7). VID is a heterogeneous disorder characterized by a decreased concentration of all immunoglobulin isotypes and a predominant $\mathrm{T}$ cell disorder: it usually leads to an increased susceptibility to bacterial infections of the respiratory and gastro-intestinal tracts. Several candidate genes had been screened (LIF, Ikaros and Eos) but no evident aetiology could be identified. By doing whole exome sequencing, Chen et al., and then our team, managed to identify NFKB2 mutations as the plausible cause of DAVID syndrome $(8,9)$. Nuclear factor of kappa light polypeptide gene enhancer in B-cells 2 (NFKB2) is a pleiotropic transcription factor present in almost all cell types but its precise roles remain incompletely understood. Two other groups also reported NFKB2 mutations in patients with similar phenotypes making the involvement of NFKB2 in DAVID syndrome highly likely even if the endocrine phenotype was not systematically studied $(10,11)$. However the precise mechanisms whereby this factor may lead to endocrine deficits remain unclear. While Nfkb2 is indeed expressed in the developing and adult pituitary, we found that a mouse model carrying a C-terminal mutation of $N f k b 2$ (Lym1 mouse) had immune deficiency but no pituitary anomaly (9). This was not in favour of a developmental defect, even if mouse and human models, though close, do not systematically share the same steps of pituitary development. The fact that one patient presented with alopecia could be in favour of an auto-immune defect, which does not explain why corticotroph function appears selectively affected. Interestingly, other patients from our cohort with the same phenotype did not harbour any NFKB2 mutation. 


\section{Novel mode of transmission}

\section{Lethality of the first homozygous LHX4 mutation}

The family of LIM (Lin-11, Isl-1, Mec-3) domain transcription factors has been described several years ago, and mutations of these transcription factors are well identified as being responsible for CPHD. LIM domain transcription factors are involved in the early steps of pituitary development, but they are not pituitary specific, which explains why patients usually do not present with a pure pituitary phenotype. In recent years, a growing number of studies reported new heterozygous mutations, and clearly emphasized the wide range of phenotypes induced by mutations of LIM homeobox 4 (LHX4): for instance two recent studies have shown that patients with LHX4 mutations (W204X and $R 84 X)(12,13)$ could present delayed ACTH deficiency, up to the age of 16 years. However, all of these variants were present in a heterozygous state, and it was extrapolated that homozygous LHX4 mutations were likely to be lethal (the murine model of homozygous Lhx4 inactivation leads to an early post-natal death due to respiratory distress).

Very recently, the first report of a homozygous LHX4 mutation was published. The family reported by Gregory et al. (12) carried a novel homozygous missense variant (c.377C > T, p.T126M): two children died after 3 weeks of age with severe panhypopituitarism despite optimal replacement therapy; the patients were also carrying mid-facial hypoplasia and lung anomalies. Surprisingly, functional studies, performed in an in vitro heterologous system, did not reveal any difference with WT LHX4 in the activation of target promoters. However, the variant had never been reported in SNP databases in a homozygous state, and the severity of the pituitary and pulmonary phenotypes were suggestive of the involvement of this new LHX 4 variant in the disease.

\section{Syndromic CPHD in LHX3 compound heterozygotes}

LIM homeobox 3 (LHX3) is a LIM domain transcription factor, known to be involved in the early steps of pituitary development. Several homozygous mutations of $L H X 3$ have been reported in patients with pituitary deficiencies and extra-pituitary anomalies such as deafness, limited neck rotation or pituitary stalk interruption syndrome (PSIS).

Sobrier et al. reported the case of a boy with a syndromic CPHD due to a compound heterozygosity of $L H X 3$. The boy presented severe respiratory failure after birth, associated with GH and TSH deficiency. Genetic analysis revealed a paternally inherited $c .252-3 C>G$ change: this variant disrupts an acceptor splice site, which leads to a short protein inducing a dominant negative effect in vitro. The maternally inherited p.C118YLHX3 variant led to a protein with impaired transactivational ability in vitro. Combination of both modified the transactivational activities of LHX3. Further outcome revealed ACTH deficiency, deafness and limited neck rotation, as previously described. The case was thus not atypical in its clinical presentation. Interestingly, the father, who was heterozygous, was presenting mild phenotypic signs, with limited neck rotation, suggesting that a dominant negative effect of c.252-3C $>$ GLHX3 was also occurring in the heterozygous state. Finally, this study was also the first to our knowledge in which genetic data allowed a prenatal diagnosis on LHX3 that was performed five years later (14).

\section{Novel phenotypes}

\section{GH deficiency in patients with SOX2 mutations}

Over recent years, SRY-box 2 (SOX2) has become a major player in the pituitary stem cells compartment. SOX2 is early expressed in the developing Rathke's pouch and the hypothalamus: more specifically, SOX2 expression is observed around the lumen, in the presumptive zone of pituitary progenitors where it could be involved in their maintenance. SOX2 expression profile could make it a credible candidate for patients carrying pituitary deficiencies, even if its presumed roles in progenitors would suggest that its absence would lead to a very severe phenotype. In 2006, heterozygous SOX2 mutations were reported for the first time in six patients with pituitary deficiencies and pituitary hypoplasia. Surprisingly, the pituitary phenotype was modest with isolated hypogonadotroph hypogonadism. Extra-pituitary phenotype included bilateral microphthalmia, corpus callosum hypoplasia and inconstant intellectual disability (15). Since then, only one report described a male with a partial GH deficiency and complete luteinizing hormone (LH)/ follicle-stimulating hormone (FSH) deficiency, but normal anterior pituitary on MRI. Extra-pituitary phenotype was consistent with SOX2 mutations and revealed bilateral anophthalmia. The patient was carrying a novel heterozygous deletion of a single cytosine base at position c.905 of SOX2 (p.P302Rfs *69). The protein encoded was lacking the DNA-binding domain, a sufficient evidence to consider that this variant was responsible for the phenotype (16). 
Pituitary stalk interruption in patients with CHARGE syndrome

CHARGE (Coloboma, Heart defect, Atresia choanae, Retarded growth and development, Genital hypoplasia, Ear anomalies/deafness) is an autosomal dominant syndrome associating to variable degrees coloboma of the eye, heart malformations, atresia of the choanae, genital and ear abnormalities, and delayed growth and development. Chromodomain helicase DNA-binding protein-7 (CHD7) mutations have been associated with this syndrome in about two thirds of cases. Pituitary deficiencies have previously been reported in patients with CHARGE syndrome, mainly with hypogonadotroph hypogonadism, but also with GH or ACTH deficiencies. This phenotype was expected, as $\mathrm{CHD} 7$ is expressed during hypothalamicpituitary development, where it interacts with SOX2. Gregory et al. reported for the first time two novel $\mathrm{CHD} 7$ variants in patients with CHARGE syndrome and ectopic posterior pituitary: the first patient presented with mild central hypothyroidism, complete GH deficiency, and anterior pituitary hypoplasia associated with ectopic posterior pituitary; this male patient was carrying a heterozygous p.732A CHD7 variant; his mother, although heterozygous for this variant had no feature of CHARGE syndrome nor pituitary deficiency. The second patient was carrying a $c$. IVS35+6T $>C$ CHD7 variant and GH, TSH, ACTH and LH/FSH deficiencies. MRI revealed the same characteristics as the first patient. The variant was likely responsible for abnormal splicing. It was concluded that patients with CHARGE syndrome should be tested systematically for pituitary deficiencies. In contrast, as no patient with septo-optic dysplasia (SOD) but no CHARGE syndrome was presenting with $C H D 7$ mutations, it seems unnecessary to look for $C H D 7$ mutations in all patients with SOD.

\section{Novel aetiologies involving actors known to be associated with other phenotypes}

\section{The eye: a pituitary phenotype associated with PAX6 mutations?}

Paired box 6 (PAX6) is a well-known regulator of eye development. PAX6 heterozygous mutations have been reported in patients with a wide range of eye defects. The fact that PAX6 is a regulator of the early differentiation of somatotroph, lactotroph and thyrotroph cells made it a good candidate in patients with eye defects and pituitary deficiency. This has been reported in patients with an unexpected phenotype: five patients from the same large family, with heterozygous PAX6 mutations and eye anomalies, were indeed presenting with isolated partial corticotroph deficiency, but normal GH, PRL and TSH functions (17). For the first time, Takagi et al. identified PAX6 anomalies in two patients with GH deficiency. The first patient was aged three when he was diagnosed with GH deficiency and bilateral cryptorchidism; MRI showed pituitary hypoplasia and a thin stalk. Genetic analysis identified a heterozygous p.N116S PAX6 variant, which had impaired transactivation capacities in comparison with WT in in vitro studies. Interestingly, the mother, who was carrying the same variant, was safe of pituitary disease, suggesting that penetrance was incomplete (or that pituitary deficiency was due to another aetiology). The authors also reported a second patient with isolated GH deficiency diagnosed at the age of three, and a $310 \mathrm{~kb}$ deletion of PAX6 enhancer gene. MRI was normal except for the anterior pituitary, which was hypoplastic (18).

\section{The gonadotroph axis: the complex pituitary spectrum of patients with PROKR2, FGF8 and FGFR1 variants}

Recent years have emphasized the roles of the traditionally well known 'hypogonadotroph hypogonadism' genes in patients with CPHD associated or not with SOD. In a large cohort of 103 patients with SOD for instance, Raivio et al. (19) identified $7.8 \%$ of aetiologies due to mutations of these genes. Thus these genes cannot anymore be considered as responsible for isolated hypogonadotroph hypogonadism only; moreover, other pituitary deficiencies should be looked for in patients with Kallmann syndrome due to mutations of these genes.

The Prokineticin pathway: PROKR2 variants $>$ Prokinecitin receptor 2 (PROKR2) is a $G$ protein-coupled receptor involved in sexual and olfactory bulb development in mice, and necessary for proper neuronal migration and angiogenesis. Human mutations of PROK2 have been reported in isolated hypogonadotroph hypogonadism. Given the roles of PROK2 and PROKR2 in angiogenesis, it was plausible to consider that mutations of such genes could be observed in patients with PSIS. Our group reported for the first time three heterozygous PROKR2 variants $(L 173 R, R 85 H, A 51 T)$ in patients with GH, TSH and ACTH deficiencies (in some of them); MRI showed PSIS in all patients (20). Later on, McCabe et al. reported five other PROKR2 variants ( $p . A 51 T, p . R 85 L, p . L 173 R$, and p.R268C, p.G371R) in 11 patients with SOD and congenital hypopituitarism (from isolated GH deficiency to panhypopituitarism). Since then, four novel heterozygous 
variants of PROKR2 (R85C, R85G, R248Q and $R 268 C$ ) were reported in patients presenting with a wide range of phenotypes from hypogonadotroph hypogonadism associated with SOD, to panhypopituitarism without SOD; of note, some of the patients had corpus callosum hypoplasia and optic nerve anomalies, and one of these patients also presented with central diabetes insipidus $(19,21)$. Interestingly, the majority of these variants had already been reported in patients with isolated hypogonadotroph hypogonadism. Surprisingly, murine models with homozygous inactivation of Prokr2 showed predominantly normal hypothalamo-pituitary development and terminal cell differentiation, except for LH secreting cells (22). The role of PROKR2 in pituitary development, though highly plausible, remains to date speculative.

The fibroblast growth factor family: FGF8 and FGFR1 variants - Fibroblast growth factor 8 (FGF8) is a member of the ubiquitously expressed FGF family of signalling molecules and its receptors. FGF8 is a major player in the development of GnRH neurons. It is also necessary for proper LHX3 expression. Mutations of FGF8 have been reported in patients with Kallmann syndrome. Four years ago, McCabe et al. reported for the first time FGF8 mutations in two unrelated patients: the first female had holoprosencephaly, microcephaly, absence of corpus callosum, ACTH deficiency, diabetes insipidus shortly after birth and delayed TSH deficiency. The anterior pituitary was hypoplastic on MRI. She was carrying a homozygous p.R189H FGF8 variant. The second was found to have SOD at the age of six, absence of corpus callosum, hypoplastic optic nerves, partial GH deficiency and normal anterior pituitary on MRI: the patient was carrying a heterozygous p.Q216EFGF8 mutation. In mouse, Fgf8 expression was observed in the developing Rathke's pouch. Mouse embryos carrying a hypomorphic allele of Fgf8 presented severe abnormalities of the anterior pituitary during development: decreased size, but surprisingly with defects in the terminal differentiation of LH expressing cells only (23). The same team then reported a novel FGF8 heterozygous synonymous change (p.T72T) in a patient with GH, TSH and ACTH deficiency, pubertal delay, and a bulky anterior pituitary; despite the synonymous nature of the change, this variant was predicted to alter splicing and ligand signalling activity (19).

FGF receptor 1 (FGFR1) is a tyrosine kinase receptor belonging to the FGF family. It is the main receptor mediating FGF8 signalling. It is also expressed during Rathke's pouch development. Raivio et al. (19) were the first to describe three FGFR1 variants in patients with SOD and hypogonadotroph hypogonadism: two of these patients had GH deficiency, and one had panhypopituitarism; two had corpus callosum agenesis, whereas the third had microphtalmia. Since then, three novel heterozygous FGFR1 variants (p.R448W, p.S107L and p.P772S) were reported in four unrelated patients with anterior pituitary hypoplasia, ectopic posterior pituitary and pituitary deficiencies from $\mathrm{GH}$ and $\mathrm{LH} / \mathrm{FSH}$ deficiencies to panhypopituitarism (21). Interestingly, these variants had already been reported in patients with isolated hypogonadotroph hypogonadism suggesting the incomplete penetrance in terms of pituitary phenotype in patients carrying mutations of genes coding for the FGF family.

\section{Holoprosencenphaly-related genes: pituitary deficiencies in patients without holoprosencephaly}

Shh-signalling pathway and its targets, GLI zinc-transcription factors, are involved in brain development. $\mathrm{SHH}$, and to a lower extent, GLI2 mutations have been reported in patients with holoprosencephaly, a severe neurological disorder characterized by a failure of midline division of the forebrain. Transforming growth interacting factor (TGIF) mutations have also been reported in $1 \%$ of patients with holoprosencephaly (24). SHH pathway is also involved in the early steps of pituitary development, which made it and its targets good candidates in patients with pituitary deficiencies. The involvement of GLI2 during pituitary development and the phenotype of patients carrying GLI2 variants have been recently reviewed (25). For some of these variants, pathogenicity remains uncertain. Briefly, the phenotype of patients carrying certain heterozygous GLI2 pathogenic variants usually included at least GH deficiency, anterior pituitary hypoplasia and ectopic posterior pituitary, and postaxial polydactyly (25). The reasons why some variants could lead to a less or more severe phenotype are currently unknown. To our knowledge, only one heterozygous $S H H$ mutation (c.1279G $>A$, p.G427R) was reported in a female patient who was presenting with CPHD, anterior pituitary hypoplasia, and no stigmata of holoprosencephaly. The father, who was heterozygous for the same variant, was safe of pituitary disease, confirming the incomplete penetrance. In the same study, the TGIF heterozygous p.Q267X variant was also reported for the first time in a female patient with the same pituitary phenotype and a single central incisor (25).

Very recently, Bashamboo et al. reported the first heterozygous nonsense mutation in the gene coding for the SHH-signalling protein CDON (cell adhesion associated, 
oncogene regulated): $\mathrm{CDON}$ is a cell surface SHH-binding protein that promotes SHH-signalling activity. The patient was diagnosed with a PSIS, neonatal hypoglycaemia, cholestasis and GH, TSH and ACTH deficiencies. Mutations of $C D O N$ had been previously reported in six patients with holoprosencephaly. Interestingly, the mother, who was also carrying the mutation, had been operated on in childhood for strabismus. As this variant was absent from control databases, the authors concluded that it was likely responsible for the phenotype (26).

\section{Conclusions and perspectives}

This review is a brief summary of the major novelties reported in the last 5 years on genetic causes of combined pituitary hormone deficiencies. It clearly demonstrates that much work still needs to be performed: newly involved transcription factors only includes two novel candidates, and whereas two main new types of actors have been identified (immunoglobulin superfamily, ciliary $G$ protein-coupled receptors), the understanding of how they might be involved in hypopituitarism genesis remains poor; this will hamper the identification of other proteins from the same family that might be responsible for pituitary phenotypes. This also likely explains, at least in part, why only 10\% of CPHD aetiologies have been identified to date. Based on phenotypes described in the literature and our experience within the 'Genhypopit' network, we defined an algorithm allowing the clinician and the geneticist to look for the most appropriate genes to sequence when a congenital hypopituitarism is diagnosed (27). Even when such an algorithm is constantly updated, such a strategy is necessarily flawed since recent data suggest that alterations of some genes initially thought to be involved in a specific phenotype can actually lead to a wider range of phenotypes, and that actors that were not even supposed to play a role in pituitary development are actually probably involved.

In recent years, the need for using new methods of aetiological identification was indeed emphasized: the classical candidate gene approach, and the extrapolation from murine models have shown their limits. New mechanisms/actors have all been identified via wholegenome approaches, and these new techniques are likely to further increase the rate of identification of the causes of congenital hypopituitarism. But each technique has its own limits. Array comparative genomic hybridization was developed to identify segmental genomic copy number variations (gain or loss) such as structural rearrangements or complex chromosomal aneuploidies. The main limitations of this technique are the impossibility to detect balanced translocations and the risk of 'over-detection', i.e. detecting large numbers of rearrangements of low or undetermined clinical significance. This risk is similar with whole-exome sequencing: this technique is based on the assumption that $85 \%$ of mutations are located in coding regions of the genome. However, reporting new variants in a single patient does not mean pathogenicity of this variant, and requires confirmation by a similar finding in other subjects, presenting with similar phenotypes. Confirmatory steps by bioinformatics analysis based on a usually large dataset of results can thus be highly challenging: it is indeed always difficult to perform the appropriate selection of a reasonable number of potential candidates out of thousands. The proof of pathogenicity is the ultimate challenging step. The American College of Medical Genetics and Genomics Guidelines have recently been published to standardize the strong or weak evidence to identify pathogenic variants (28). Of note, functional in vitro studies, which were considered the gold standard, are now becoming more and more difficult to perform, in the lack of obvious targets of these new actors. As mentioned in the present review, no precise mechanism could indeed be shown for the majority of newly reported actors in the aetiology of CPHD.

\section{Declaration of interest}

The authors declare that there is no conflict of interest that could be perceived as prejudicing the impartiality of the review.

\section{Funding}

This work was supported by grants from the 'Association pour le Développement de la Recherche au centre hospitalier de Marseille' (A.DE.RE.M) and from the Advancing Science through Pfizer-Investigator Research Exchange (ASPIRE) research award.

\section{References}

1 Kelberman D, Rizzoti K, Lovell-Badge R, Robinson IC \& Dattani MT. Genetic regulation of pituitary gland development in human and mouse. Endocrine Reviews 200930 790-829. (doi:10.1210/er.2009-0008)

2 Sun Y, Bak B, Schoenmakers N, van Trotsenburg AS, Oostdijk W, Voshol P, Cambridge E, White JK, le Tissier P, Gharavy SN et al. Loss-of-function mutations in IGSF1 cause an X-linked syndrome of central hypothyroidism and testicular enlargement. Nature Genetics 201244 1375-1381. (doi:10.1038/ng.2453)

3 Joustra SD, Schoenmakers N, Persani L, Campi I, Bonomi M, Radetti G, BeckPeccoz P, Zhu H, Davis TM, Sun Y et al. The IGSF1 deficiency syndrome: characteristics of male and female patients. Journal of Clinical Endocrinology and Metabolism 201398 4942-4952. (doi:10.1210/jc.2013-2743)

4 Mukhopadhyay S, Wen X, Ratti N, Loktev A, Rangell L, Scales SJ \& Jackson PK. The ciliary G-protein-coupled receptor Gpr161 negatively regulates the Sonic hedgehog pathway via cAMP signaling. Cell 2013 152 210-223. (doi:10.1016/j.cell.2012.12.026) 
5 Karaca E, Buyukkaya R, Pehlivan D, Charng WL, Yaykasli KO, Bayram Y, Gambin T, Withers M, Atik MM, Arslanoglu I et al. Whole-exome sequencing identifies homozygous GPR161 mutation in a family with pituitary stalk interruption syndrome. Journal of Clinical Endocrinology and Metabolism 2015100 E140-E147. (doi:10.1210/jc.2014-1984)

6 Webb EA, AlMutair A, Kelberman D, Bacchelli C, Chanudet E, Lescai F, Andoniadou CL, Banyan A, Alsawaid A, Alrifai MT et al. ARNT2 mutation causes hypopituitarism, post-natal microcephaly, visual and renal anomalies. Brain 2013136 3096-3105. (doi:10.1093/brain/awt218)

7 Quentien MH, Delemer B, Papadimitriou DT, Souchon PF, Jaussaud R, Pagnier A, Munzer M, Jullien N, Reynaud R, Galon-Faure N et al. Deficit in anterior pituitary function and variable immune deficiency (DAVID) in children presenting with adrenocorticotropin deficiency and severe infections. Journal of Clinical Endocrinology and Metabolism 201297 E121-E128. (doi:10.1210/jc.2011-0407)

8 Chen K, Coonrod EM, Kumanovics A, Franks ZF, Durtschi JD, Margraf RL, Wu W, Heikal NM, Augustine NH, Ridge PG et al. Germline mutations in NFKB2 implicate the noncanonical NFKB pathway in the pathogenesis of common variable immunodeficiency. American Journal of Human Genetics 201393 812-824. (doi:10.1016/j.ajhg.2013.09.009)

9 Brue T, Quentien MH, Khetchoumian K, Bensa M, Capo-Chichi JM, Delemer B, Balsalobre A, Nassif C, Papadimitriou DT, Pagnier A et al. Mutations in NFKB2 and potential genetic heterogeneity in patients with DAVID syndrome, having variable endocrine and immune deficiencies. BMC Medical Genetics 201415 139. (doi:10.1186/s12881-014-0139-9)

10 Lee CE, Fulcher DA, Whittle B, Chand R, Fewings N, Field M, Andrews D, Goodnow CC \& Cook MC. Autosomal-dominant B-cell deficiency with alopecia due to a mutation in NFKB2 that results in nonprocessable p100. Blood 2014124 2964-2972. (doi:10.1182/blood-2014-06-578542)

11 Liu Y, Hanson S, Gurugama P, Jones A, Clark B \& Ibrahim MA. Novel NFKB2 mutation in early-onset CVID. Journal of Clinical Immunology 201434 686-690. (doi:10.1007/s10875-014-0064-x)

12 Gregory LC, Humayun KN, Turton JP, McCabe MJ, Rhodes SJ \& Dattani MT. Novel lethal form of congenital hypopituitarism associated with the first recessive LHX4 mutation. Journal of Clinical Endocrinology and Metabolism 2015100 2158-2164. (doi:10.1210/jc.2014-4484)

13 Takagi M, Ishii T, Inokuchi M, Amano N, Narumi S, Asakura Y, Muroya K, Hasegawa Y, Adachi M \& Hasegawa T. Gradual loss of ACTH due to a novel mutation in LHX4: comprehensive mutation screening in Japanese patients with congenital hypopituitarism. PLoS ONE 20127 e46008. (doi:10.1371/journal.pone.0046008)

14 Sobrier ML, Brachet C, Vie-Luton MP, Perez C, Copin B, Legendre M, Heinrichs C \& Amselem S. Symptomatic heterozygotes and prenatal diagnoses in a nonconsanguineous family with syndromic combined pituitary hormone deficiency resulting from two novel LHX3 mutations. Journal of Clinical Endocrinology and Metabolism 201297 E503-E509. (doi:10.1210/jc.2011-2095)

15 Kelberman D, Rizzoti K, Avilion A, Bitner-Glindzicz M, Cianfarani S, Collins J, Chong WK, Kirk JM, Achermann JC, Ross R et al. Mutations within Sox $2 / \mathrm{SOX} 2$ are associated with abnormalities in the hypothalamo-pituitary-gonadal axis in mice and humans. Journal of Clinical Investigation 2006116 2442-2455. (doi:10.1172/JCI28658)

16 Macchiaroli A, Kelberman D, Auriemma RS, Drury S, Islam L, Giangiobbe S, Ironi G, Lench N, Sowden JC, Colao A et al. A novel heterozygous SOX2 mutation causing congenital bilateral anophthalmia, hypogonadotropic hypogonadism and growth hormone deficiency. Gene 2014534 282-285. (doi:10.1016/j.gene. 2013.10.043)

17 Hergott-Faure L, Borot S, Kleinclauss C, Abitbol M \& Penfornis A. Pituitary function and glucose tolerance in a family with a PAX6 mutation. Annales d'endocrinologie 201273 510-514. (doi:10.1016/ j.ando.2012.10.001)

18 Takagi M, Nagasaki K, Fujiwara I, Ishii T, Amano N, Asakura Y, Muroya K, Hasegawa Y, Adachi M \& Hasegawa T. Heterozygous defects in PAX6 gene and congenital hypopituitarism. European Journal of Endocrinology 2015172 37-45. (doi:10.1530/EJE-14-0255)

19 Raivio T, Avbelj M, McCabe MJ, Romero CJ, Dwyer AA, Tommiska J, Sykiotis GP, Gregory LC, Diaczok D, Tziaferi V et al. Genetic overlap in Kallmann syndrome, combined pituitary hormone deficiency, and septo-optic dysplasia. Journal of Clinical Endocrinology and Metabolism 201297 E694-E699. (doi:10.1210/jc.2011-2938)

20 Reynaud R, Jayakody SA, Monnier C, Saveanu A, Bouligand J, Guedj AM, Simonin G, Lecomte P, Barlier A, Rondard P et al. PROKR2 variants in multiple hypopituitarism with pituitary stalk interruption. Journal of Clinical Endocrinology and Metabolism 201297 E1068-E1073. (doi:10.1210/jc.2011-3056)

21 Correa FA, Trarbach EB, Tusset C, Latronico AC, Montenegro LR, Carvalho LR, Franca MM, Otto AP, Costalonga EF, Brito VN et al. FGFR1 and PROKR2 rare variants found in patients with combined pituitary hormone deficiencies. Endocrine Connections 20154 100-107. (doi:10.1530/EC-15-0015)

22 McCabe MJ, Gaston-Massuet C, Gregory LC, Alatzoglou KS, Tziaferi V, Sbai O, Rondard P, Masumoto KH, Nagano M, Shigeyoshi Y et al. Variations in PROKR2, but not PROK2, are associated with hypopituitarism and septo-optic dysplasia. Journal of Clinical Endocrinology and Metabolism 201398 E547-E557. (doi:10.1210/jc.2012-3067)

23 McCabe MJ, Gaston-Massuet C, Tziaferi V, Gregory LC, Alatzoglou KS, Signore M, Puelles E, Gerrelli D, Farooqi IS, Raza J et al. Novel FGF8 mutations associated with recessive holoprosencephaly, craniofacial defects, and hypothalamo-pituitary dysfunction. Journal of Clinical Endocrinology and Metabolism 2011 96 E1709-E1718. (doi:10.1210/jc.2011-0454)

24 Aguilella C, Dubourg C, Attia-Sobol J, Vigneron J, Blayau M, Pasquier L, Lazaro L, Odent S \& David V. Molecular screening of the TGIF gene in holoprosencephaly: identification of two novel mutations. Human Genetics 2003112 131-134. (doi:10.1007/s00439-002-0862-8)

25 Arnhold IJ, Franca MM, Carvalho LR, Mendonca BB \& Jorge AA. Role of GLI2 in hypopituitarism phenotype. Journal of Molecular Endocrinology 201554 R141-R150. (doi:10.1530/JME-15-0009)

26 Bashamboo A, Bignon-Topalovic J, Rouba H, McElreavey K \& Brauner R. A nonsense mutation in the hedgehog receptor CDON associated with pituitary stalk interruption syndrome. Journal of Clinical Endocrinology and Metabolism 2016101 12-15. (doi:10.1210/jc.2015-2995)

27 Reynaud R, Gueydan M, Saveanu A, Vallette-Kasic S, Enjalbert A, Brue T $\&$ Barlier A. Genetic screening of combined pituitary hormone deficiency: experience in 195 patients. Journal of Clinical Endocrinology and Metabolism 200691 3329-3336. (doi:10.1210/jc.2005-2173)

28 Richards S, Aziz N, Bale S, Bick D, Das S, Gastier-Foster J, Grody WW, Hegde M, Lyon E, Spector E et al. Standards and guidelines for the interpretation of sequence variants: a joint consensus recommendation of the American College of Medical Genetics and Genomics and the Association for Molecular Pathology. Genetics in Medicine 201517 405-424. (doi:10.1038/gim.2015.30)
Received 6 November 2015

Revised version received 15 December 2015

Accepted 5 January 2016 